Научная статья

УДК 1: 159.9:82.0 (571.54)

DOI: $10.18101 / 1994-0866-2021-2-70-78$

\title{
ОБ ИНТЕЛЛЕКТУАЛЬНО-КРЕАТИВНОЙ СОСТАВЛЯЮЩЕЙ БУРЯТСКОГО ХАРАКТЕРА
}

\section{(C) Серебрякова Зоя Александровна}

доктор филологических наук, и. о. профессора, Восточно-Сибирский государственный институт культуры Россия, 670031, г. Улан-Удэ, ул. Терешковой, 1 serebryakovaza@mail.ru

\author{
(C) Серебрякова Юлия Александровна \\ доктор философских наук, профессор, \\ Бурятская государственная сельскохозяйственная академия им. В. Р. Филиппова \\ Россия, 670034, г. Улан-Удэ, ул. Пушкина, 8 \\ serebr.yu.a@yndex.ru
}

\begin{abstract}
Аннотация. Проблема бурятского характера актуальна, вызывает неизменный интерес, но недостаточно изучена, особенно на теоретическом уровне и в его современных проявлениях. Это относится и к чертам, относящимся к интеллектуальнокреативной составляющей характера, требующей от исследователя более глубокого знакомства с бытием этноса, нежели описание элементов материальной культуры, обычаев, обрядов и т. п. Наиболее обстоятельные и объективные описания этих черт бурятского характера принадлежат Н. А. Бестужеву, что обусловлено длительностью его пребывания в Бурятии, близким знакомством с жизнью и бытом аборигенов, искренним и глубоким познавательным интересом к ним, отсутствием какой-либо предвзятости. Интересные замечания о тяге бурят к знаниям были сделаны в конце XIX - начале XX в. Отдельные наблюдения позволяют судить о трансформации некоторых интеллектуально-креативных способностей бурят в постсоветское время. Большой вклад в художественное осмысление данной составляющей бурятского характера внес национальный роман Ч. Цыдендамбаева, создавшего образ профессионального ученого Д. Банзарова. Таким образом, благодаря трудам ряда авторов XIX - начала XX в., а также бурятским романистам объективированы важные черты интеллектуально-творческого потенциала бурятского характера.

Ключевые слова: буряты, бурятский характер, менталитет, интеллектуальнокреативная составляющая, ученый, декабрист, писатель, роман, публицистика, очерк

\section{Для цитирования}

Серебрякова 3. А., Серебрякова Ю. А. Об интеллектуально-креативной составляющей бурятского характера // Вестник Бурятского государственного университета. Философия. 2021. Вып. 2. С. 70-78.
\end{abstract}

Примечательными чертами современности являются глобализация и мультикультурализм, ознаменовавшие все большее сближение народов, появление объединяющих их черт, «тем не менее, - по словам Г. Д. Гачева, - в ядре своем каждый народ остается сам собой до тех пор, пока сохраняется особенный климат, времена года, пейзаж, национальная пища, этнический тип, язык, - ибо они 
3. А. Серебрякова, Ю. А. Серебрякова. Об интеллектуально-креативной составляющей бурятского характера

непрерывно питают и воспроизводят национальные склады бытия и мышления» $[1$, с. 430$]$.

Склад поведения, мышления, гамма чувств, эмоций, базовые духовные ценности, важнейшие традиции народа и т. п. сконцентрированы в его характере, который привлекает философов, ученых и служит источником вдохновения художников.

Проблема бурятского характера является актуальным, представляющим немалый интерес и слабоизученным аспектом современного научного знания. Как известно, в бурятоведческой литературе содержатся лишь некоторые сведения о национальном характере бурят, в основном традиционном, наиболее обстоятельно представленные в трудах классиков этнографии.

Между тем эта проблема имеет не только сугубо научную значимость, но и практическую, методологическую, т. к. знания о собственном характере помогают народу осмыслить и объективно оценить исторический опыт, насущные проблемы, требующие разрешения, и, наконец, определить пути дальнейшего развития с учетом факторов, связанных с особенностями этого характера.

Особенно подробно многими авторами, начиная с Д. Банзарова, описываются бережное, даже почтительное отношение бурят к природе, ее стихиям, святыням; качества характера, обусловленные кочевой цивилизацией и преобладавшим в прошлом животноводческим типом хозяйства, особенностями их верований, поколенческими, гендерными и социально-ролевыми аспектами семейных отношений; а также уважение к старшим; гостеприимство; миролюбие; уживчивость; толерантность в межэтнических отношениях, сдержанность; коллективизм; взаимовыручка; любовь к родине и др. Судя по большинству публикаций, эти качества считаются унаследованными новыми генерациями этноса и в несколько обновленном виде проявляющимися и в последнее столетие.

Обратимся к чертам, относящимся к интеллектуально-креативной составляющей характера бурят, которым в общем массиве публикаций уделяется несколько меньше внимания, поскольку такие качества, как стремление к знаниям, склонность к интеллектуальной деятельности, креативность, неотъемлемые от трудолюбия, терпения, упорства, усидчивости и настойчивости, требуют от ученого более обстоятельного знакомства с бытием этноса, нежели описание артефактов, обрядности, обычаев, многих элементов культуры повседневности и т. п., которые более привычны и доступны вниманию сторонних наблюдателей, например путешественников, и воспроизводятся ими в путевых заметках, очерках и т. д.

Не углубляясь в дискуссии психологов относительно дифференциации творчества и креативности, связи интеллекта и креативности и т. П., будем исходить из такой обобщающей позиции: «...творческие способности как один из факторов общей одаренности личности являются независимым от интеллекта феноменом. Высокий уровень творческого мышления и креативности предполагает нестандартное, быстрое и оригинальное решение возникающих задач» [2, с. 33].

Некоторое отставание в разработке аспектов, касающихся мышления, эмоционально-чувственной сферы, творческого потенциала людей проявляется при изучении многих социальных явлений. Например, «новая историческая наука», 
основы которой в 1930-х гг. были заложены М. Блоком, Л. Февром и др., раньше и более подробно изучала материальные элементы повседневной жизни разных эпох и только после этого - образ чувств и мыслей людей.

В данной статье используется понятие характера, а не непосредственно связанного с ним менталитета. Большинство исследователей понимают под менталитетом систему ценностей, доминирующее умонастроение или мироотношение народа, а понятие характера наряду с ментальными включает и поведенческие аспекты [3, с. 31].

Черты бурятского характера, относящиеся к мыслительной и творческой деятельности, на теоретическом уровне пытались осмыслить Ц. Жамцарано, В. И. Затеев, В. И. Антонов и др. Однако наиболее обстоятельно их описали декабристы.

Длительность пребывания в Бурятии, близкое знакомство с жизнью и бытом коренного населения, искренний и глубокий познавательный интерес к представителям бурятского этноса, образованность, незаурядная одаренность позволили Н. А. Бестужеву по достоинству оценить их способности. Основными их признаками, согласно положениям современной теории способностей, являются производительность, эффективность, успешность деятельности субъекта и присущие созданному им продукту надежность и качество [4, с. 10-11, 13, 198].

Декабрист отметил такие достижения бурят, как применение методов народной медицины, которые он непосредственно наблюдал и убедился в их результативности $[5$, с. 82], умение на основе речных ресурсов формировать покосы [6, с. 146], быстрое и эффективное овладение техникой малораспространенного в то время в Забайкалье земледелия [5, с. 88] и др.

Николай Александрович с одобрением, а иногда и восторженно отзывался о мастеровитости степняков. «Что же касается до их сметливости, то они далеко опередили сибиряков. Бурят - и плотник, и кузнец, и столяр, и работник у нас, и пахарь, и косец...- писал он. - Вся мебель... в нашем доме сделана бурятами, дом построен ими, у брата моего они делают экипажи, у сестры фактотум всех ее хозяйственных желаний и поделок - пастух наш - бурят по имени Ирдыней. Все заказы по части лесной... они выполняют. Чрезвычайно просто и остроумно плавят они дрова по быстрым нашим рекам, усеянным островами, отмелями, каменными грядами» [7, с. 59-60].

Особенно много точных, сделанных знатоком, всегда живо интересовавшимся техническими вопросами, наблюдений, свидетельствующих о смышлености, пытливости, любознательности бурят, приведено в очерке «Гусиное озеро», где, в частности, утверждается, что «бурят сметлив и на все способен, потому что наблюдательность развита в нем в высшей степени» [5, с. 132], подробно описывается искусная работа странствующего слесаря, чинившего чугунные чаши и при минимуме инструментов сумевшего отремонтировать емкость, совсем не имевшую дна [5, с. 89-90], а также случай, когда спутник декабриста, видя, что тот расстроен потерей трубки, быстро сделал ему и себе импровизированные трубки из подручных материалов» [5, с. 84-85].

Работы Н. А. Бестужева раскрывают и разносторонность интересов самого автора. Его перу принадлежат также несколько сравнений образа жизни бурят и 
3. А. Серебрякова, Ю. А. Серебрякова. Об интеллектуально-креативной составляющей бурятского характера

древних греков. Это, как и тот факт, что в плане умственных способностей декабрист ставил бурят «наравне со всеми лучшими племенами человеческого рода» $[5$, с. 132], показывают великодушие и благородство этого выдающегося человека, свободного от какой-либо предвзятости и высокомерия по отношению к аборигенам, которые если не явно, то латентно иногда проявляются в описаниях их образа жизни некоторыми другими авторами.

Историки справедливо отмечают, что Н. А. Бестужев «включает бурят и другие сибирские народы в число активных созидателей родного края [8, с. 201].

В своем письме к брату М. К. Кюхельбекер эмоционально делился с ним своим впечатлением о работе бурят-строителей: «Еще скажу тебе, что у нас дом для училища почти готов! Селенгинские братские - мастера не нашим плотникам чета! Решительно будет лучший дом в городе!» [9, с. 167]. В «Кратком очерке Забайкальского края» он писал об искусстве плотников, кузнецов, серебряных дел мастеров [10, с. 43]. Как видим, в большинстве цитированных фрагментов речь идет об одаренности, которая есть «интегральное проявление способностей в целях конкретной деятельности [4, с. 198].

Помимо убедительности описаний, обращает на себя внимание авторская искренность, непосредственность, точность и живость стиля не только эпистолярных, но и публицистических работ обоих декабристов. Вместе с тем в них не прослеживается стремления выявить причины интеллектуально-творческой одаренности бурят, и, по-видимому, такой задачи и не ставилось.

Несмотря на достижения психологической науки XX в., и в конце этого периода констатируется недостаточная изученность механизмов мышления $[4$, с. 9,11 , 71], хотя многие его качества (самостоятельность, глубина, гибкость, быстрота, последовательность мысли, экономичность, широта ума и др.) выявлены.

Можно в первом приближении лишь предположить, что истоки интеллектуально-креативной составляющей бурятского характера каким-то образом связаны с разнообразием природной среды, влияющей на скорость психических реакций, гибкость мышления, развитие наблюдательности и обусловливающей широту диапазона впечатлений, с идейным влиянием господствующих в регионе вероучений, шаманизма и буддизма, а также с трансграничным статусом территории Бурятии, перекрестка нескольких цивилизаций, которые тоже способствовали преодолению этнической замкнутости. Возможно, что способности к различным ремеслам обусловлены, в частности, богатством природы и недр, являющихся источником многообразия материалов для обработки, а также установившимся с течением времени сочетанием разных видов хозяйственной деятельности и т. п.

Интересные наблюдения были сделаны в конце XIX — начале XX в. Автором одного из них является известный русский писатель Н. Г. Гарин-Михайловский: «Несомненно, буряты - народ, способный к культуре. Между ними и теперь немало людей образованных» [цит. по: 11, с. 39]. На аналогичные черты характера обращали внимание и другие исследователи, среди которых чаще других цитируются фрагменты работы А. Штернберга о больших умственных способностях и тяге бурят к европейской культуре [12, с. 605-606]. 
К этому же периоду относится высказывание путешественника А. И. Термена о том, что у бурят «стремление к просвещению сказывается и в Иркутской губернии, и в Забайкальской области одинаково и всюду...» [цит. по: 13, c. 224-225].

Огромную тягу бурят к просвещению очень убедительно и ярко отразил М. Н. Хангалов, помимо научной деятельности работавший педагогом и вынужденный ежегодно отказывать многим желающим в приеме в училище из-за недостатка мест. Он писал о реакции непринятых детей как «о слезах и плаче», а также о негодовании их родителей [цит. по: 13, с. 226].

Наряду с упомянутым выше трендом, акцентирующим преемственность отмеченных черт традиционного бурятского характера, в отдельных работах фиксируется наличие разных вариантов современного характера: следование части его носителей традиционной кочевой модели и в то же время некоторая модификация этой модели в результате произошедших в России, в том числе в сфере производства трансформаций последних десятилетий. Так, М. М. Содномпилова отмечает, что большинство нынешних скотоводов прилагают минимум усилий для обеспечения работы своих хозяйств, «минимум, который лишь удерживает хозяйство от развала... не проявляют интереса к новым технологиям, к новым способам ведения хозяйства, к современным достижениям... Предложения по усовершенствованию труда... местные хозяйственники обычно встречали с недоумением: "А зачем? И так хорошо"» [14, с. 55-56].

Возможные причины такой реакции усматриваются «в отношении к жизни, присущем кочевнику», не слишком привязанному к деньгам, и в религиозных воззрениях и народных представлениях «об эфемерности такого вложения средств, как скот, и, соответственно, бессмысленности чрезмерного увеличения поголовья» $[14$, с. 56$]$.

Этот исследователь обоснованно употребляет понятие «рудименты традиционного уклада кочевой жизни» и констатирует, что «буряты давно уже не ведут кочевую жизнь - соответственно меняются фундаментальные экономические диспозиции, потребности, предпочтения и склонности: к труду, накоплению, инвестициям. Накопление стало возможным, и теперь стадо животных не является удачным вложением средств... Хозяйственники в разведении скота стремятся достичь того уровня, при котором реализация продукции будет рентабельной, а полученную прибыль вкладывают во что-нибудь более надежное, чем скот... За стадом... видится телевизор, мебель, машины, квартиры в городе и большинство мечтает о тех временах, когда уже не нужно будет "ходить за скотом", а можно будет наслаждаться теплом и уютом городских квартир» [14, с. 56].

Как известно, предпринимательская активность, предприимчивость также являются проявлениями интеллектуально-креативных способностей субъекта. К числу авторов, обративших внимание на это качество современного бурятского характера, относится Ю. Б. Рандалов, указавший на факторы, благоприятствующие их развитию: «...во-первых, наличие хороших природных и геоэкономических ресурсов края, во-вторых, наличие собственной национальной государственности, в-третьих, наличие стабильности межнациональных отношений между двумя народами, в-четвертых, достигнутый довольно высокий образова- 
3. А. Серебрякова, Ю. А. Серебрякова. Об интеллектуально-креативной составляющей бурятского характера

тельно-профессиональный производственный потенциал населения и, наконец, в-пятых, отсутствие, вернее, слабое проявление конкурентной борьбы крупного международного компрадорского и метропольного монополистического капитала, который еще не успел подобраться к Байкальскому региону» [15, с. 570].

Сказанное выше дает основания заключить, что социально-гуманитарные исследования разных лет позволили выявить важные черты интеллектуальнокреативной составляющей бурятского характера.

Большой вклад в его художественное осмысление внес национальный роман, обладающий «особыми преимуществами для исследования... национального восприятия и преображения мира», поскольку литератор, как «живая призма, отграненная народной жизнью» [1, с. 53], воспроизводит глубину, богатство, целостность и самую суть этой жизни.

Данный жанр появился в национальной литературе в 1949 г., и уже в 1952 г. в романе Ч. Цыдендамбаева «Доржи, сын Банзара» в статусе главного героя был выведен юный Д. Банзаров, а в его продолжении - «Вдали от родных степей» $(1957,1959)$ - прозаик показал казанский период его жизни. Для краткости приведем отдельные фрагменты анализа этих произведений, в которых «особенно глубоко и полно раскрывается... такая черта национального менталитета, как упорное стремление к знаниям, почитание мудрости и образованности. ...Доржи Банзаров с раннего детства проявил пытливость ума, любознательность и незаурядные интеллектуальные задатки... Доржи - истинный сын народа, издревле высоко ценящего интеллектуальное богатство... Одной из ведущих черт характера молодого ориенталиста является преданное служение науке, творческое вдохновение, с которым он занимается любимым делом» [3, с. 63, 67].

Несмотря на серьезные трудности в воспроизведении абсолютно неизведанной для национальной литературы темы, процесса научного творчества, Ч. Цыдендамбаеву удалось впервые в бурятском романе раскрыть тему науки и создать новый тип героя - профессионального ученого.

Появление романа, посвященного этой теме, носит знаковый характер. С. Д. Батомункуев правильно подчеркивает, что романному слову и романному мышлению в максимальной степени по сравнению с прочими литературными жанрами присущи рефлексивность, критическое мышление. «Именно в искусстве романа... можно проследить эволюцию мышления национальных меньшинств или, по крайней мере, их интеллектуальных элит эпохи модернизации» $[16$, c. 154$]$.

Определенным продвижением в художественном анализе интеллектуальнотворческой составляющей бурятского характера можно считать образы народных мастеров во многих исторических романах, собирателя фольклора и учителя Михаила Дорондоева из романа А. Бальбурова «Поющие стрелы», профессионального художника Минжура Жамганова, главного героя незавершенного романа Ж. Тумунова «Золотой дождь», работа над которым прервалась в 1955 г., поэта Олега Аюшеева, центрального героя романа В. Митыпова «Долина бессмертников», изобретателя и рационализатора Балты из романа Д. Эрдынеева «Большая родословная», физика Дэбшэна из романа А. Ангархаева «Вечный цвет» и др. 
Так, в образах молодых героев романа «Большая родословная» Балты и Аян В. Ц. Найдаков подчеркнул их «высокий интеллектуальный уровень, постоянный поиск истины, нового, умение трудиться самозабвенно, целиком отдавая себя делу, ясное сознание своей роли... в жизни своего народа» [17, с. 197].

Такие персонажи способствуют формированию более адекватного представления об интеллектуально-креативной составляющей бурятского характера, убедительно показывают многогранность и неисчерпаемость творческого потенциала народа. Как полагает С. Д. Батомункуев, «возможно представить историю развития бурятского романа как явление, отражающее историю модернизации ментальности бурят» [16, с. 155].

Другим ярким образцом интерпретации этих черт бурятского характера является публицистика писателя Г. Т. Башкуева, датируемая в основном постсоветским временем и показывающая преемственность отмеченных еще декабристами качеств у современных технических специалистов, в том числе в сфере информационных технологий $[18 ; 19$, с. 145-146].

Таким образом, несмотря на то, что анализ интеллектуально-креативной составляющей бурятского характера не занимает ведущего места в соответствующих источниках, в трудах мыслителей XIX — начала XX в., в отдельных публикациях постсоветского периода, а также в бурятском романе отражаются многие черты интеллектуально-творческого потенциала народа.

\section{Литература}

1. Гачев Г. Д. Национальные образы мира. Москва: Советский писатель, 1988. 448 с. Текст: непосредственный.

2. Иванченко Г. В., Казарян М. Ю., Кошелева Н. В. Творчество, профессионализм, духовность: имплицитные концепции. М.: Смысл, 2012. 192 с. Текст: непосредственный.

3. Серебрякова 3. А. Национальный характер в бурятском историческом романе. Улан-Удэ: Изд-во БГСХА им. В. Р. Филиппова, 2008. 103 с. Текст: непосредственный.

4. Шадриков В. Д. Способности человека. Москва: Институт практической психологии. Воронеж: МОДЭК, 1997. 288 с. Текст: непосредственный.

5. Бестужев Н. А. Гусиное озеро // Декабристы о Бурятии. Статьи, очерки, письма. Улан-Удэ: Бурятское кн. изд-во, 1975. С. 63-136. Текст: непосредственный.

6. Бестужев Н. А. Очерки забайкальского хозяйства // Декабристы о Бурятии. Статьи, очерки, письма. Улан-Удэ: Бурятское кн. изд-во, 1975. С. 136-158. Текст: непосредственный.

7. Бестужев Н. А. Бурятское хозяйство // Декабристы о Бурятии. Статьи, очерки, письма. Улан-Удэ: Бурят. кн. изд-во, 1975. С. 57-63. Текст: непосредственный.

8. История Бурятии / главный редактор и руководитель проекта Б. В. Базаров; редакционная коллегия А. П. Деревянко [и др.]: в 3 томах. Т. II. XVII - начало XX в. УланУдэ: Изд-во БНЦ СО РАН, 2011. 624 с. Текст: непосредственный.

9. Кюхельбекер М. К. - Кюхельбекеру В. К. Письмо. 16 июня 1843 г. // Декабристы о Бурятии. Статьи, очерки, письма. Улан-Удэ: Бурятское кн. изд-во, 1975. С. 167-168. Текст: непосредственный.

10. Кюхельбекер М. К. Краткий очерк Забайкальского края // Декабристы о Бурятии. Статьи, очерки, письма. Улан-Удэ: Бурятское кн. изд-во, 1975. С. 25-53. Текст: непосредственный. 
3. А. Серебрякова, Ю. А. Серебрякова. Об интеллектуально-креативной составляющей бурятского характера

11. Матханова Н. П. Буряты в сибирской мемуаристике ХIX века // Исторический опыт взаимодействия народов и цивилизаций: к 350-летию присоединения Бурятии к России: сборник статей / научный редактор Б. В. Базаров; ответственный редактор Л. В. Курас. Улан-Удэ; Иркутск: Оттиск, 2011. С. 38-42. Текст: непосредственный.

12. Штернберг А. Буряты // Формы национального движения в современных государствах. Австро-Венгрия. Россия. Германия / под редакцией А. И. Кастелянского. Санкт-Петербург: Общественная польза, 1910. С. 601-624. Текст: непосредственный.

13. Андреев В. И. История бурятской школы (1804-1962 гг.). Улан-Удэ: Бурят. кн. изд-во, 1964. 586 с. Текст: непосредственный.

14. Содномпилова М. М. Этнические сообщества Бурятии: модернизация традиционного мировоззрения // Philosophy and Social Science in the Developing Countries. УланУдэ: Изд-во БНЦ СО РАН, 2010. 114 с. С. 54-57. Текст: непосредственный.

15. Рандалов Ю. Б. Этносоциальные и этнополитические процессы в среде бурятского народа // Буряты / ответственные редакторы Л. Л. Абаева, Н. Л. Жуковская; Ин-т этнологии и антропологии им. Н. Н. Миклухо-Маклая. Москва: Наука, 2004. С. 568-577. Текст: непосредственный.

16. Скрынникова Т. Д., Батомункуев С. Д., Варнавский П. К. Бурятская этничность в контексте социокультурной модернизации (советский период): коллективная монография / составитель Т. Д. Скрынникова. Улан-Удэ: Изд-во БНЦ СО АН СССР, 2004. 216 с. Текст: непосредственный.

17. Найдаков В. Ц. Путь к роману. История формирования бурятской прозы. Новосибирск: Наука, 1985. 261 с. Текст: непосредственный.

18. Серебрякова 3. А., Серебрякова Ю. А. Позиция писателя (о публицистике Г. Башкуева) // Интеллигенция и проблемы социокультурной модернизации современного общества: материалы XII Международной научной конференции «Байкальская встреча», посвященной 85-летию доктора философских наук, профессора И. И. Осинского (Улан-Удэ, 12-16 сентября 2018 г.) / научный редактор М. В. Бадмаева. Улан-Удэ: Изд-во Бурят. гос. ун-та, 2018. С. 278-283. Текст: непосредственный.

19. Серебрякова Ю. А. Феномен национального. Улан-Удэ: Издательскополиграфический комплекс ВСГИК, 2018. 160 с. Текст: непосредственный.

Статья поступила в редакицию 15.04.2021; одобрена после рецчензирования 29.04.2021; принята к публикации 11.05.2021.

\section{ON INTELLECTUAL AND CREATIVE COMPONENTS \\ OF THE BURYAT NATIONAL CHARACTER}

Zoya A. Serebryakova

Dr. Sci. (Phil.), Acting Prof.,

East-Siberian State Institute of Culture

1 Tereshkovoy St., Ulan-Ude 670031, Russia

serebryakovaza@mail.ru

Yulia A. Serebryakova

Dr. Sci. (Philos.), Prof.,

Filippov Buryat State Agricultural Academy

8 Pushkina St., Ulan-Ude 670034, Russia

serebr.yu.a@yndex.ru 
Abstract. The problem of the Buryat national character arouses constant interest, but is insufficiently studied, especially at the theoretical level and in its modern manifestations. This also concerns the intellectual and creative components of the character, which requires the deep insight into the everyday life of the ethnic group rather than description of the elements of material culture, customs, rituals, etc. The most detailed and objective descriptions of these traits of the Buryat character belong to N. A. Bestuzhev, this is due to the length of his stay in Buryatia, close acquaintance with the life of aborigines, genuine cognition interest in them, the absence of any bias. Interesting remarks about their thirst for knowledge were made in the late 19th - early 20th centuries. Individual observations allow us to trace the transformation of some intellectual and creative abilities of the Buryats in the post-Soviet period. National novels as a whole, and the works of the writer Ch. Tsydendambaev, who created the image of the professional scientist D. Banzarov in particular, made a great contribution to the artistic understanding of this component of the Buryat character. Thus, the works of a number of authors of the 19th - early 20th centuries, as well as of the Buryat novelists objectified the important features of the intellectual and creative potential of the Buryat character.

Keywords: Buryats, the Buryat character, mentality, intellectual and creative components, scientist, Decembrist, writer, novel, opinion journalism, sketch story

For citation

Serebryakova Z. A., Serebryakova Yu. A. On Intellectual and Creative Components of the Buryat National Character. Bulletin of Buryat State University. Philosophy. 2021; 2: 70-78 (In Russ.).

The article was submitted 15.04.2021; approved after reviewing 29.04.2021; accepted for publication 11.05.2021. 